\title{
Impact of Quality and Government Subsidies on Elderly Care Services
}

\author{
Mengna Li, Liyun Wu* \\ School of Energy Science \& Engineering, Henan Polytechnic University, Jiaozuo 454003, Henan Province, China \\ *Corresponding author: Liyun Wu, jitwly@hpu.edu.cn
}

\begin{abstract}
In order to solve the problem of imbalance resource allocation and service income in the elderly care service industry, this article establishes three service income models in different situations for a single provider and a single integrator while considering the quality as well as government subsidies. The results showed that government subsidies can significantly improve quality efforts and service income with a mutual restriction between quality and service income. Government subsidies would have an impact on the quality, and they are more conducive to the service income of providers. When government subsidies are less than $80 \%$ of the service income, the incentive effect is better.
\end{abstract}

Keywords: Revenue model; Pension service supply chain; Quality preference; Government subsidies

Publication date: August 2021; Online publication: August 30, 2021

\section{Introduction}

With the increasing aging population, the problem of providing for the aged in China has become increasingly prominent. There are many problems in the pension service, but the emergence of the pension service supply chain makes the pension service resources coordinated and greatly reduces the pension cost. At this stage, pension related industries continue to appear, and the pension service supply chain is prosperous and developing. However, currently, the main problem which hinders the development of the pension service supply chain is on how to avoid a large number of repeated low-quality pension services and look for targeted government support policies ${ }^{[1]}$.

The development of pension service supply chain mainly focuses on the quality of pension service, and the related theories mainly emphasize on the behavioral factors and supply chain. The service integrator, service provider, and consumers form a pension service supply chain. From the research of behavioral factors, more attention is paid to the impact of the behaviors of the members on their service revenue ${ }^{[2-4]}$. From the perspective of supply chain, the quality game relationship among members of the supply chain is mainly studied ${ }^{[5,6]}$ in addition to service quality decision-making ${ }^{[7]}$, quality control coordination ${ }^{[8]}$, quality risk, and so on. Nash equilibrium and Stackelberg game were often used in supply chain quality research. In addition to quality, the rapid development of the supply chain of pension service is inseparable from the support of national government policies. At this stage, the government has carried out reform pilot work in homes and on community pension service where the promulgation and implementation of government policies have greatly promoted the development of the pension service supply chain. Government decisionmaking plays a role in ensuring ${ }^{[9]}$ and coordinating ${ }^{[10]}$ the quality of pension service, and it also has an impact on the price of pension service and social welfare. However, at present, China's pension service industry is still in its infancy, and the implementation of government policies is still in the exploratory stage. There are some problems in the government policies, such as the lack of pertinence and obvious effect. 
The above research shows the importance of quality and government subsidies in the supply chain of pension service, but there is no research on considering government subsidies based on the behavioral factors of supply chain members in the existing pension service supply chain. Therefore, in this paper, a game model of pension service revenue is constructed, the pension service supply chain composed of a single pension service provider and a pension service integrator is studied, the behavior characteristics of quality preference are introduced, the optimal quality effort and service revenue under three situations including no government subsidies, government subsidies to provider, and government subsidies to integrator are analyzed, and a comparative analysis of their mutual influence is made.

\section{Hypotheses}

This paper examined a two-level pension service supply chain system composed of a single service provider and a single service integrator as shown in Figure 1. The government provides subsidies as an independent individual. The market demand of pension service is determined by service cost, service quality, and market uncertainty.

\section{Service provider $\stackrel{\text { Service products }}{\leftarrow \text { Order }}$ Service integrator}

Figure 1. Business flow chart of pension service supply chain

The basic hypotheses are as follows:

(1) The market demand of pension service supply chain is $d=\alpha-\beta \mathrm{q}_{2}+\gamma\left(\mathrm{b}_{1} e_{1}+\mathrm{b}_{2} e_{2}\right)+\varepsilon$. The influence of price is considered, but the specific analysis of the price is not done; that is, assuming that the price is determined, the influence on market demand is determined.

(2) Suppose $e_{i}^{j}$ is the degree of quality efforts of both parties under different decisions that is expressed by the letters $j=N, P, I$ where $N$ means no government subsidies, $P$ means government subsidies to provider, and $I$ means government subsidies to integrator.

(3) Considering quality preferences as $\lambda_{i}$, it is divided into quality avoidance, quality neutrality, and quality preference. $\lambda_{i}=1$ means quality is neutral, $\lambda_{i}<1$ means quality avoidance, and $\lambda_{i}>1$ means quality preference.

(4) Government subsidies are determined according to the market demand. It is assumed that subsidies act directly on the service provider regardless of the impact of government subsidies on the market demand. The impact is reflected in the quality efforts and service revenue of the service provider, and there is a long-term cooperative relationship between the provider and the integrator.

(5) Assuming $q_{2}>c_{2}, q_{1}>c_{1}, q_{2}>c_{2}+q_{1}$ when the above conditions are met, it is in line with the law of market operation.

The cost function of quality effort is $\mathrm{T}_{i}=\frac{1}{2} c_{1} e_{1}^{2}+c_{2} e_{2}$. For the convenience of the following discussion, the symbols and explanations are shown in Table 1. 
Table 1. Symbols and descriptions

\begin{tabular}{cl}
\hline Symbol & \multicolumn{1}{c}{ Meaning and explanation } \\
\hline$\alpha$ & Basic market demand \\
$\gamma$ & The influence of selling price on market demand \\
$\varepsilon$ & The impact of quality effort on market demand \\
$q_{1}$ & The mean value is 0 \\
$q_{2}$ & Unit price provided to integrator \\
$e_{i}$ & Unit service charge \\
$b_{i}$ & Quality efforts of both parties \\
$e_{i}^{j}$ & Elasticity coefficient of quality effort \\
$c$ & Quality efforts of both parties under different decisions \\
$w_{i}^{j}$ & Quality effort cost of service supply chain members $\left(c_{1}>0, \quad c_{2}>0\right)$ \\
$\mathrm{T}_{\mathrm{i}}$ & Benefits of service supply chain members under different decisions \\
$\lambda_{i}$ & Quality effort cost function \\
$\theta$ & Quality preference of service supply chain members \\
\hline
\end{tabular}

\section{Supply chain model of pension service}

\subsection{Supply chain model of pension service without government subsidy}

Based on the above assumptions, the game model of profit function is established using the Nash equilibrium theory under the condition that both the provider and integrator pursue the maximum of their own interests as shown in formula (1) and (2).

$$
\begin{gathered}
W_{1}=d\left(\mathrm{q}_{1}-\mathrm{c}_{1}\right)-\frac{T_{1}}{\lambda_{1}} \\
W_{2}=d\left(\mathrm{q}_{2}-q_{1}-\mathrm{c}_{2}\right)-\frac{T_{2}}{\lambda_{2}}
\end{gathered}
$$

From equations (1) and (2), considering the influence of the supply chain quality preference on quality effort and revenue when the elderly service supply chain pursues the maximization of their own interests without government subsidies, the optimal solution is that without government subsidies, the optimal quality effort and the optimal service revenue of the elderly service supply chain are as follows:

$$
\begin{gathered}
e_{1}^{O *}=\frac{-c_{2}-\gamma b_{1} c_{1} \lambda_{1}+\gamma b_{1} q_{1} \lambda_{1}}{c_{1}} \\
W_{1}^{O^{*}=} \frac{c_{2}^{2}+2 \gamma c_{2}\left(c_{1}-q_{1}\right) \lambda_{1}\left(\mathrm{~b}_{1}+\mathrm{b}_{2}+\gamma \mathrm{b}_{2}^{2} \lambda_{2}\right)+\gamma^{2}\left(-\mathrm{b}_{1}^{2} \mathrm{q}_{1} \lambda_{1}+2 b_{2}^{2}\left(\mathrm{q}_{1}-\mathrm{q}_{2}\right) \lambda_{2}\right)+\left(\mathrm{c}_{1}-\mathrm{q}_{1}\right) \lambda_{1}\left(\mathrm{c}_{1}\left(-2(\alpha+\varepsilon)+2 \beta q_{2}+\gamma^{2} \mathrm{~b}_{1}^{2} \lambda_{1}\right)\right.}{2 c_{1} \lambda_{1}} \\
W_{2}^{O^{*}}=\frac{2\left(c_{2}+q_{1}-q_{2}\right)\left(\gamma\left(b_{1}+b_{2}\right) c_{2}+\frac{c_{2}^{2}}{\lambda_{2}}+\gamma^{2} b_{2}^{2}\left(\mathrm{c}_{2}+\mathrm{q}_{1}-\mathrm{q}_{2}\right)^{2} \lambda_{2}-c_{1}\left(\alpha+\varepsilon-\beta \mathrm{q}_{2}+\gamma^{2} \mathrm{~b}_{1}^{2}\left(\mathrm{c}_{1}-\mathrm{q}_{1}\right) \lambda_{1}\right)\right.}{2 c_{1}}
\end{gathered}
$$


Proof: In order to obtain the optimal solution, the first and second derivative of supplier's and integrator's quality effort can be obtained from equations (1) and (2) where the first derivative is set equal to zero (see equations (7) and (8)). The optimal quality effort can be obtained by solving equations (3) and (4). By substituting the supplier's and integrator's quality effort into equations (1) and (2), the optimal service revenue will be obtained (see equations (5) and (6)).

$$
\frac{\partial W_{1}}{\partial \mathrm{e}_{1}}=\gamma b_{1}\left(-\mathrm{c}_{1}+\mathrm{q}_{1}\right)-\frac{2 c_{2}+2 c_{1} e_{1}^{o}}{2 \lambda_{1}}=0
$$

$$
\frac{\partial W_{2}}{\partial e_{2}}=\gamma b_{2}\left(-c_{2}-\mathrm{q}_{1}+\mathrm{q}_{2}\right)-\frac{2 c_{2}+2 c_{1} e_{2}^{O}}{2 \lambda_{2}}=0
$$

When there is no government subsidy, the optimal quality effort of the supplier, $e_{1}^{O^{*}}$, and the optimal revenue of the integrator, $W_{2}^{O^{*}}$, are positively correlated with the quality preference, $\lambda_{1}$, of the supplier. The optimal quality effort of the integrator, $e_{2}^{O^{*}}$, and the optimal revenue of the supplier, $W_{1}^{O^{*}}$, are positively correlated with the quality preference of the integrator, $\lambda_{2}$. The degree of quality effort increases with the increase of the quality preference, and the influence of the quality preference on the revenue is also positively correlated.

Proof: Taking the derivatives of equations (3) and (4), (5), and (6), respectively, the results are as follows:

$$
\begin{array}{ll}
\frac{\partial e_{1}^{O^{*}}}{\partial \lambda_{1}}=\frac{-\gamma b_{1} c_{1}+\gamma b_{1} q_{1}}{c_{1}}>0 & \frac{\partial W_{2}^{O^{*}}}{\partial \lambda_{1}}=\frac{\gamma b_{1}\left(-\gamma \mathrm{b}_{1} \mathrm{c}_{1}+\gamma \mathrm{b}_{1} \mathrm{q}_{1}\right)\left(-\mathrm{c}_{2}-q_{1}+\mathrm{q}_{2}\right)}{c_{1}}>0 \\
\frac{\partial e_{2}^{O *}}{\partial \lambda_{2}}=\frac{-\gamma b_{2} c_{2}-\gamma b_{2} q_{1}+\gamma b_{2} q_{2}}{c_{1}}>0 & \frac{\partial W_{1}^{O^{*}}}{\partial \lambda_{2}}=\frac{\gamma b_{2}\left(-\gamma \mathrm{b}_{2} \mathrm{c}_{2}-\gamma b_{2} q_{1}+\gamma \mathrm{b}_{2} \mathrm{q}_{2}\right)\left(-\mathrm{c}_{1}+\mathrm{q}_{1}\right)}{c_{1}}>0
\end{array}
$$

That is to say, the quality effort of the supplier, $e_{1}^{O^{*}}$, and the revenue of the integrator, $W_{2}^{O^{*}}$, are positively correlated with the quality preference, $\lambda_{1}$. The quality effort of the integrator, $e_{2}^{O^{*}}$, and the revenue of the supplier, $W_{1}^{O^{*}}$, are positively correlated with the quality preference, $\lambda_{2}$.

\subsection{Supply chain model of pension service with government subsidies to service provider}

In order to support the development of the pension industry, the government subsidizes the providers of pension service institutions where $\theta$ is the subsidy for a single service object. The profit function of the provider and integrator can be established as follows:

$$
\begin{aligned}
& W_{1}^{P}=d\left(\mathrm{q}_{1}+\theta-\mathrm{c}_{1}\right)-\frac{T_{1}}{\lambda_{1}} \\
& W_{2}^{P}=d\left(\mathrm{q}_{2}-q_{1}-\mathrm{c}_{2}\right)-\frac{T_{2}}{\lambda_{2}}
\end{aligned}
$$

In the case of government subsidies to pension service provider, both the provider and integrator pursue the maximization of their own interests. Formula (9) and (10) show that the optimal quality effort and the optimal service revenue of government subsidies to the pension service supply chain provider are as follows:

$$
\begin{gathered}
e_{1}^{P^{*}}=\frac{-c_{2}+\gamma \lambda_{1} b_{1} \theta-\gamma \lambda_{1} b_{1} c_{1}+\gamma \lambda_{1} b_{1} q_{1}}{c_{1}} \quad \text { (11) } \quad e_{2}^{P *}=\frac{-c_{2}-\gamma \lambda_{2} b_{2} c_{2}-\gamma \lambda_{2} b_{2} q_{1}+\gamma \lambda_{2} b_{2} q_{2}}{c_{1}} \\
W_{1}^{P^{*}}=\frac{2 \lambda_{1}\left(\theta-\mathrm{c}_{1}+\mathrm{q}_{1}\right)\left(c_{1}\left(\alpha+\varepsilon-\beta \mathrm{q}_{2}\right)+\gamma\left(-\left(\mathrm{b}_{1}+\mathrm{b}_{2}\right) \mathrm{c}_{2}-\gamma \mathrm{b}_{2}^{2}\left(\mathrm{c}_{2}+\mathrm{q}_{1}-\mathrm{q}_{2}\right) \lambda_{2}\right)\right)+c_{2}^{2}+\gamma^{2} \lambda_{1}^{2} b_{1}^{2}\left(\theta-\mathrm{c}_{1}+\mathrm{q}_{1}\right)^{2}}{2 c_{1} \lambda_{1}}
\end{gathered}
$$




$$
W_{2}^{P^{*}}=\frac{2\left(\mathrm{c}_{2}+\mathrm{q}_{1}-\mathrm{q}_{2}\right)\left(-c_{1}\left(\alpha+\varepsilon-\beta \mathrm{q}_{2}-\gamma^{2} \mathrm{~b}_{1}^{2} \lambda_{1}\right)+\gamma b_{1}\left(c_{2}-\gamma \mathrm{b}_{1}\left(\theta+\mathrm{q}_{1}\right) \lambda_{1}\right)\right)}{2 c_{1}}+\frac{\left(\mathrm{c}_{2}+\gamma b_{2} \lambda_{2}\left(\mathrm{c}_{2}+\mathrm{q}_{1}-\mathrm{q}_{2}\right)\right)^{2}}{2 c_{1} \lambda_{2}}
$$

When the supplier is subsidized, the quality effort of the supplier, $e_{1}^{P^{*}}$, is positively related to its own quality preference, $\lambda_{1}$, and the government subsidy, $\theta$. The quality effort of the integrator, $e_{2}^{P^{*}}$, is positively related to its own quality preference, $\lambda_{2}$, and it has nothing to do with government subsidy, $\theta$. The service revenue of the supplier, $W_{1}{ }^{*}$, is positively correlated with the quality preference of the integrator, $\lambda_{2}$, and the government subsidy, $\theta$. The service revenue of the integrator, $W_{2}^{P^{*}}$, is positively correlated with the quality preference of the supplier, $\lambda_{1}$, and the government subsidy, $\theta$.

Proof: Taking the derivatives of the quality preference and government subsidy, respectively from equation (11) and (12).

$$
\begin{array}{lc}
\frac{\partial e_{1}^{P^{*}}}{\partial \lambda_{1}}=\frac{\gamma b_{1}\left(\theta+q_{1}-\mathrm{c}_{1}\right)}{c_{1}} & \frac{\partial e_{1}^{P *}}{\partial \theta}=\frac{\gamma b_{1} \lambda_{1}}{c_{1}} \\
\frac{\partial e_{2}^{P *}}{\partial \lambda_{2}}=-\frac{\gamma b_{2}\left(\mathrm{c}_{2}+\mathrm{q}_{1}-\mathrm{q}_{2}\right)}{c_{1}} & \frac{\partial e_{2}^{P *}}{\partial \theta}=0
\end{array}
$$

Based on the above derivation, according to its no negativity and basic assumptions $\left(q_{2}-c_{2}>q_{1}\right.$, $\left.q_{1}>c_{1}\right)$, the first three results are all positive, and the derivatives of the quality effort of the integrator and the government subsidy are zero. Therefore, when the supplier is subsidized, the quality effort of the supplier is positively related to its own quality preference and the government subsidy while the quality effort of the integrator is positively related to its own quality preference, and the government subsidy has no effect on the quality effort of the integrator.

$$
\begin{array}{cr}
\frac{\partial W_{1}^{P^{*}}}{\partial \lambda_{2}}=-\frac{\gamma^{2} b_{2}^{2}\left(\theta-\mathrm{c}_{1}+\mathrm{q}_{1}\right)\left(\mathrm{c}_{2}+\mathrm{q}_{1}-\mathrm{q}_{2}\right)}{c_{1}} & \frac{\partial W_{2}^{P^{*}}}{\partial \lambda_{1}}=-\frac{\gamma^{2} b_{1}^{2}\left(\theta-\mathrm{c}_{1}+\mathrm{q}_{1}\right)\left(\mathrm{c}_{2}+\mathrm{q}_{1}-\mathrm{q}_{2}\right)}{c_{1}} \\
\frac{\partial W_{1}^{P^{*}}}{\partial \theta}=\frac{-c_{2}^{2}+\gamma^{2} b_{1}^{2}\left(\theta-\mathrm{c}_{1}+\mathrm{q}_{1}\right)^{2} \lambda_{1}^{2}}{2 c_{1} \lambda_{1}^{2}} & \frac{\partial W_{2}^{P^{*}}}{\partial \theta}=-\frac{\gamma^{2} b_{1}^{2}\left(\mathrm{c}_{2}+\mathrm{q}_{1}-\mathrm{q}_{2}\right) \lambda_{1}}{c_{1}}
\end{array}
$$

When $q_{2}-c_{2}>q_{1}$ and $q_{1}>c_{1}$, the above derivations are greater than 0 . The service revenue of the provider is positively related to the quality preference of the integrator and the government subsidy while the service revenue of the integrator is positively related to the quality preference of the provider and the government subsidy.

\subsection{Supply chain model of pension services with government subsidies to service integrator}

In order to better develop the pension industry, it is assumed that the government subsidizes the integrators where $\theta$ is the subsidy for a single service object. The profit function of provider and integrator can be established as follows:

$$
\begin{gathered}
W_{1}^{\mathrm{I}^{*}}=d\left(\mathrm{q}_{1}-\mathrm{c}_{1}\right)-\frac{T_{1}}{\lambda_{1}} \\
W_{2}^{\mathrm{I}^{*}}=d\left(\mathrm{q}_{2}+\theta-q_{1}-\mathrm{c}_{2}\right)-\frac{T_{2}}{\lambda_{2}}
\end{gathered}
$$


When the government subsidizes the integrator, the integrator pursues the maximization of its own interests. From equation (15) and (16), it can be concluded that the optimal quality effort and the optimal revenue of the integrator of the pension service supply chain are as follows:

$$
\begin{gathered}
e_{1}^{I^{*}}=\frac{-c_{2}-\gamma \lambda_{1} b_{1} c_{1}+\gamma \lambda_{1} b_{1} q_{1}}{c_{1}} \quad \text { (17) } \quad e_{2}^{I^{*}}=\frac{-c_{2}+\gamma \theta \lambda_{2} b_{2}-\gamma \lambda_{2} b_{2} c_{2}}{c_{1}}+\frac{-\gamma \lambda_{2} b_{2} q_{1}+\gamma \lambda_{2} b_{2} q_{2}}{c_{1}} \\
W_{1}^{I^{*}}=\frac{1}{2 \lambda_{1} c_{1}}\left(c_{2}^{2}+\gamma^{2} \mathrm{~b}_{1}^{2}\left(\mathrm{c}_{1}-\mathrm{q}_{1}\right)^{2} \lambda_{1}^{2}-2\left(\mathrm{c}_{1}-\mathrm{q}_{1}\right) \lambda_{1}\left(\mathrm{c}_{1}\left(\alpha+\varepsilon-\beta \mathrm{q}_{2}\right)+\gamma\left(-\left(\mathrm{b}_{1}+\mathrm{b}_{2}\right) \mathrm{c}_{2}+\gamma \mathrm{b}_{2}^{2}\left(\theta-\mathrm{c}_{2}-\mathrm{q}_{1}+\mathrm{q}_{2}\right) \lambda_{2}\right)\right)\right. \\
W_{2}^{I^{*}}=\left(\theta-\mathrm{c}_{2}-\mathrm{q}_{1}+\mathrm{q}_{2}\right)\left(\alpha+\varepsilon-\beta \mathrm{q}_{2}-\frac{\gamma b_{1}\left(\mathrm{c}_{2}+\gamma \mathrm{b}_{1}\left(\mathrm{c}_{1}-\mathrm{q}_{1}\right) \lambda_{1}\right)}{c_{1}}\right)+\frac{\left(\mathrm{c}_{2}+\gamma \mathrm{b}_{2}\left(-\theta+\mathrm{c}_{2}+\mathrm{q}_{1}-\mathrm{q}_{2}\right) \lambda_{2}\right)^{2}}{2 c_{1} \lambda_{2}}
\end{gathered}
$$

The process of proof is similar to that of subsidizing suppliers, so it will not be repeated.

\section{Numerical analysis}

Representative values are used. The quality effort and service return under different conditions are described and illustrated by numerical simulation. Assuming $\gamma=70, b_{1}=1, b_{2}=1, c_{1}=200, c_{2}=100$, $q_{1}=300, q_{2}=500, \alpha=200, \beta=4, \varepsilon=0, \lambda_{1} \in[1,10], \lambda_{2} \in[1,10]$, and $\theta \in[200,500]$.

The service revenue under different strategies is shown in Table 2 (assuming that the quality preference values of the provider and integrator are the same; that is, only government subsidies are considered).

Through the analysis of the data, it can be seen that when government subsidies are given to a party, the revenue of the party receiving subsidies is positively correlated with the government subsidies while the service revenue of the party not receiving subsidies is positively correlated with the government subsidies. When the proportion of government subsidies is higher than $80 \%$ of the sales price, the revenue growth will weaken. However, when the proportion of government subsidies is lower than $80 \%$ of the sales price, the government subsidies have a better incentive effect. Government subsidies have an impact on the quality preference. From the perspective of service revenue, government subsidies are more beneficial to the provider.

Table 2. Quality effort and revenue under different strategies

\begin{tabular}{ccccccccccc}
\hline & \multicolumn{4}{c}{ No government subsidy } & \multicolumn{3}{c}{ Subsidizing provider } & \multicolumn{3}{c}{ Subsidizing integrator } \\
\hline \multirow{2}{*}{ Sales price ratio } & $e_{1}^{O}$ & $e_{2}^{O}$ & $W_{1}^{O}$ & $W_{2}^{O}$ & $e_{1}^{P}$ & $W_{1}^{P}$ & $W_{2}^{P}$ & $e_{2}^{I}$ & $W_{1}^{I}$ & $W_{2}^{I}$ \\
\hline 0 & 34.5 & 34.5 & 180525 & 180525 & 34.5 & 180525 & 180525 & 34.5 & 180525 & 180525 \\
$10 \%$ & - & - & - & - & 52 & 362650 & 303025 & 52 & 303025 & 362650 \\
$20 \%$ & - & - & - & & 69.5 & 606025 & 425525 & 69.5 & 425525 & 606025 \\
$40 \%$ & - & - & - & - & 104.5 & 1276525 & 670525 & 104.5 & 670525 & 1276525 \\
$60 \%$ & - & - & - & & 139.5 & 2192025 & 915525 & 139.5 & 915525 & 2192025 \\
$80 \%$ & - & - & - & - & 174.5 & 3352525 & 1160525 & 174.5 & 1160525 & 3352525 \\
$100 \%$ & - & - & - & - & 209.5 & 4758025 & 1405525 & 209.5 & 1405525 & 4758025 \\
\hline
\end{tabular}

\section{Conclusion}

When a supplier and integrator have their own quality preferences, the government, as a separate subject, can give certain subsidies to the supplier and integrator, respectively. The following conclusions are drawn: 
(1) There are optimal quality efforts and optimal service revenue in the game model of pension service supply chain with and without government subsidies; (2) When the proportion of government subsidies is higher than $80 \%$, the increase of service revenue slows down whereas when the proportion of government subsidies is lower than $80 \%$, the government subsidies play a greater incentive role; (3) The results show that there is a positive correlation between quality preference, quality effort, and service revenue. By analyzing the difference of quality effort and service revenue between the provider and integrator, it can be concluded that considering quality preference and government subsidies are more beneficial to the provider's revenue.

This paper only discussed about the impact of quality preference and government subsidies on quality effort and service revenue. Although the impact of price was considered, no analyses were carried out. The follow-up would analyze the situation of government subsidies under the influence of quality preference and price. A cross-analysis of quality effort and service revenue between providers and integrators can also be considered when there is no government subsidy or government subsidies for different service providers.

\section{Disclosure statement}

The authors declare that there is no conflict of interest.

\section{References}

[1] Wang L, 2013, Research on the Demand, Supply and Utilization of Home Care Services Based on the "Service Chain" Theory. Journal of Population, 35(2): 49-59.

[2] Xing P, 2017, Research on Quality Control Strategy of Service Supply Chain Considering Quality Preference and Social Responsibility. Northeastern University.

[3] Balouch S, Rifaat E, Chen HL, et al., 2019, Social Networks and Loneliness in People with Alzheimer's Dementia. International Journal of Geriatric Psychiatry, 34(5): 666-73.

[4] Fu S, 2019, Action Characteristics and Collaborative Governance Challenges of China's Pension Service Policy Actors: A Quantitative Analysis of Text Based on the Perspective of Policy Network. Journal of Nantong University (Social Science Edition), 35(04): 75-84.

[5] Zhang Z, Lv J, Shi Y, 2016, Quality Control Coordination of Pension Service Supply Chain Based on Reward and Punishment Contract. Industrial Engineering, 19(05): 58-64.

[6] Guo Q, Wang X, 2018, Game Analysis of Private Pension Service Supply Based on Financial Subsidies. Systems Engineering, 36(10): 42-52.

[7] Liu WH, Xie D, 2013, Quality Decision of Logistics Service Supply Chain with Service Quality Guarantee. International Journal of Production Research, 5(5): 1618-34.

[8] Lee CH, Rhee BD, Cheng TCE, 2013, Quality Uncertainty and Quality-Compensation Contract for Supply Chain Coordination. European Journal of Operational Research, 228(3): 582-91.

[9] Baker SK, Weech-Maldonado R, Mor V, 2005, Market Competition and Quality of Care in the Nursing Home Industry. Journal of Health Care Finance, 32(1): 67-81.

[10] Sheu JB, Chou YH, Hu CC, 2005, An Integrated Logistics Operational Model for Green-Supply Chain Management. Transportation Research Part E Logistics and Transportation Review, 41(4): 287-313. 